\title{
Action of hormonal therapy in amyotrophic lateral sclerosis: a systematic review
}

\author{
(iD) Kátia de Vasconcelos ${ }^{1}$ \\ D. Acary Souza Bulle Oliveira ${ }^{2}$ \\ (D) Luiz Fernando Portugal Fuchs ${ }^{1}$ \\ (iD) Ricardo Santos Simões ${ }^{3}$ \\ (iD) Manuel de Jesus Simoes ${ }^{1}$ \\ (iD) Manoel loão Batista Castello Girão ${ }^{1}$ \\ (iD) lose Maria Soares Júnior ${ }^{3}$ \\ (iD) Edmund Chada Baracat ${ }^{3}$
}

\begin{abstract}
1. Departamento de Ginecologia, Escola Paulista de Medicina/Universidade Federal de São Paulo; São Paulo, SP, Brasil 2. Departamento de Neurologia e Neurocirurgia, Escola Paulista de Medicina/Universidade Federal de São Paulo; São Paulo, SP, Brasil 3. Departamento de Ginecologia e Obstetrícia, Hospital das Clínicas, Faculdade de Medicina da Universidade de São Paulo; São Paulo, SP, Brasil.
\end{abstract}

http://dx.doi.org/10.1590/1806-9282.66.11.1589

\section{SUMMARY}

Amyotrophic Lateral Sclerosis (ALS) is a fatal disease characterized by muscle weakness, atrophy, fasciculations, and decreased reflexes due to upper and lower motor neurons death. It can be present in both sexes (55-65 years), but with predominance in males. However, in female patients, ALS presents its first symptoms when they are already postmenopausal, when then the incidence ratio of the disease is practically equal between the sexes, which leads to a probable involvement of sex hormones in the development and protection against ALS. The aim of this systematic review, which used the PRISMA consensus and NOS (New Castle-Ottawa Scale) score, was to evaluate the evidence of the action of hormone therapy in women with ALS. The Medline and Cochrane databases were accessed from March 2019 to June 2019, and only full-text articles in Spanish, English, and Portuguese were included. Only four articles matched our inclusion criteria. Postmenopausal women who used exogenous estrogen did not have the same protective factor as women still under the action of endogenous estrogen in the same age group. There was also no increase in the survival of these women.

KEYWORDS: Amyotrophic Lateral Sclerosis. Gonadal Steroid Hormones. Hormone Replacement Therapy.

\section{INTRODUCTION}

Amyotrophic Lateral Sclerosis (ALS) is a fatal neurodegenerative disease characterized by the progressive degeneration of the upper and lower motor neurons in the motor cortex and spinal cord. It may be sporadic, which corresponds to $90 \%$ of cases, or familial, mostly autosomal dominant, which corresponds to $10 \%$ of cases. The disease initially presents itself with localized muscle weakness, progressing to stiffness and paralysis, and eventually compromising swallowing and diaphragm movements, which leads patients to die within 2 to 5 years due to respiratory failure ${ }^{1}{ }^{3}$.

In both its etiology and pathogenesis, the influence of sex hormones can be noted. Some data corroborate 
the idea of hormonal influence, such as the later onset of the disease in women, usually around 70 years old, when they are already in menopause. While for men, the age of disease's onset is between 55 and 65 years, and cases may occur in younger individuals $\mathbf{1}^{\mathbf{3}}$.

Another evidence of the influence of sex hormones on the disease is the men/women ratio (2:1). Concerning the differences of individuals affected by ALS, the number of affected males is superior to that of females up until a certain stage of life, i.e., around 60 years, when most women have already entered menopause, and that's when the number of affected individuals between men and women decreases, and the ratio almost equals when we consider the aging/menopause factor for women. In cases where younger individuals were affected, we also found a high prevalence of males. Another factor is survival time, which is also longer among female patients ${ }^{1},{ }^{2}, 4$.

The combination of these reported factors and others lead us to believe not only in the influence of sex hormones on ALS but also in a neuroprotective action of estrogens on motor neurons $\mathbf{1}^{\mathbf{2}}{ }^{\text {. Our review aims }}$ to analyze the possible protective action of hormone therapy on Amyotrophic Lateral Sclerosis.

\section{METHODS}

This systematic review was reviewed and approved by the Research Ethics Committee (CEP) of the Federal University of São Paulo - Paulista School of Medicine (UNIFESP-EPM) under CEP number 2289090919.

The PRISMA (Preferred Reporting Items for Systematic Reviews and Meta-Analysis) recommendation was used to complete the systematic review ${ }^{5}$.

\section{Databases}

For the identification and selection of studies analyzing the ALS outcome in women using hormone therapy, the Medline and Cochrane primary electronic databases were accessed from March 2019 to June 2019. There was no restriction on the publication year. Only articles whose full text could be retrieved and that had been published in Spanish, English, or Portuguese were considered. The search strategies and mesh terms used are shown in box 1 .

Medline/Pubmed: (Amyotrophic Lateral Sclerosis OR Lou-Gehrigs Disease Gehrigs Disease OR Amyotrophic Lateral Sclerosis, Guam Form OR Amyotrophic Lateral Sclerosis Parkinsonism Dementia Complex 1 OR Guam Disease OR Disease, Guam OR Amyotrophic
Lateral Sclerosis With Dementia OR Sclerosis, Amyotrophic Lateral OR Charcot Disease OR Motor Neuron Disease, Amyotrophic Lateral Sclerosis) AND (Gonadal Hormones OR Progesterone OR Estrogens OR Agonists, Estrogen Receptor OR Receptor Agonists, Estrogen OR Estrogen Effect OR Estrogenic Effect)

Cochrane: Amyotrophic lateral sclerosis AND Gonadal hormones

\section{BOX 1. SEARCH STRATEGIES AND DATABASES.}

Medline/Pubmed: (Amyotrophic Lateral Sclerosis OR Lou-Gehrigs Disease Gehrigs Disease OR Amyotrophic Lateral Sclerosis, Guam Form OR Amyotrophic Lateral Sclerosis Parkinsonism Dementia Complex 1 OR Guam Disease OR Disease, Guam OR Amyotrophic Lateral Sclerosis With Dementia OR Sclerosis, Amyotrophic Lateral OR Charcot Disease OR Motor Neuron Disease, Amyotrophic Lateral Sclerosis) AND (Gonadal Hormones OR Progesterone OR Estrogens OR Agonists, Estrogen Receptor OR Receptor Agonists, Estrogen OR Estrogen Effect OR Estrogenic Effect)

Cochrane: Amyotrophic lateral sclerosis AND Gonadal hormones

\section{Article retrieval}

Two researchers conducted the study selection, the evaluation of titles and abstracts obtained from the search strategies in the consulted databases, independently and blindly, obeying the established inclusion criteria and selecting the articles with potential relevance. A manual search was performed by reviewing the references (narrative or systematic) and the selected articles. Observational studies were included in the evaluation (Figure 1).

\section{Characteristics of selected studies and risk of} bias assessment

Information on author, publication year, type of study, number of patients and gender, menarche and menopause age, use of hormone therapy, duration of hormone therapy, and mean age are shown in Table $1^{16}{ }_{-}$. The assessment of the risk of bias of the studies was conducted using the Newcastle Ottawa Scale Critical Assessment Checklist (NOS), considering studies consistent when they achieved a score $\geq 6$ and inconsistent when there was a score $<6$ (Table 1). The following domains of risk bias were contemplated in the assessment: patient selection (generalization and applicability), study group comparability, outcome assessment methods (cohort studies), proof of exposure (case-control), and appropriate follow-up ${ }^{10}$. 
FIGURE 1. CHARACTERISTICS OF THE SELECTED STUDIES

\begin{tabular}{|c|c|c|c|c|c|c|c|c|}
\hline $\begin{array}{l}\text { Author and } \\
\text { publication } \\
\text { year }\end{array}$ & $\begin{array}{l}\text { Study } \\
\text { type }\end{array}$ & Country & $\begin{array}{l}\text { Number of } \\
\text { cases/controls } \\
q(n)\end{array}$ & $\begin{array}{l}\text { Mean age } \\
\text { cases/con- } \\
\text { trols, in years } \\
( \pm \text { SD) }\end{array}$ & $\begin{array}{l}\text { Menarche } \\
\text { age, in } \\
\text { years } \\
( \pm S D)\end{array}$ & $\begin{array}{l}\text { Menopause } \\
\text { age, in years } \\
( \pm S D)\end{array}$ & $\begin{array}{l}\text { Number of cases/control in } \\
\text { hormone therapy }(\Delta T)\end{array}$ & NOS \\
\hline $\begin{array}{l}\text { Rooney et } \\
\text { al. }{ }^{6}\end{array}$ & $\begin{array}{l}\text { Case- } \\
\text { control }\end{array}$ & $\begin{array}{l}\text { Neth- } \\
\text { erlands } \\
\text { Ireland } \\
\text { Italy }\end{array}$ & $\begin{array}{l}\text { Cases: } n=653 \\
\text { Controls: } \\
n=1217\end{array}$ & $\begin{array}{l}\text { Cases: } 65.3 \\
\text { Controls: } 64.7\end{array}$ & $\begin{array}{l}\text { Cases: } 13 \\
\text { Controls: } 13\end{array}$ & $\begin{array}{l}\text { Cases:49,5 } \\
( \pm 5.5) \\
\text { Controls:49,3 } \\
( \pm 5,7)\end{array}$ & $\begin{array}{l}\text { Cases: } n=93 \text { (NA) } \\
\text { Controls: } n=207 \text { (NA) }\end{array}$ & 8 \\
\hline $\begin{array}{l}\text { De Jong et } \\
\text { al. }{ }^{7}\end{array}$ & $\begin{array}{l}\text { Case- } \\
\text { control }\end{array}$ & $\begin{array}{l}\text { Nether- } \\
\text { lands }\end{array}$ & $\begin{array}{l}\text { Cases: } n=209 \\
\text { Controls: } n=672\end{array}$ & $\begin{array}{l}\text { Cases: } 65.4 \\
\text { Controls: } 63.4\end{array}$ & $\begin{array}{l}\text { Cases: } 13 \\
\text { Controls: } 13\end{array}$ & $\begin{array}{l}\text { Cases: } 50 \\
\text { Controls: } 51\end{array}$ & NA & 8 \\
\hline Popat et al. ${ }^{8}$ & $\begin{array}{l}\text { Case- } \\
\text { control }\end{array}$ & USA & $\begin{array}{l}\text { Cases: } n=62 \\
\text { Controls: } n=131\end{array}$ & $\begin{array}{l}\text { Cases: } 67,5 \\
\text { Controls: } 67,6\end{array}$ & $\begin{array}{l}\text { Cases: } 13 \\
\text { Controls: } 13\end{array}$ & $\begin{array}{l}\text { Cases: } 51,4 \\
\text { Controls: } 52,2\end{array}$ & $\begin{array}{l}\text { Cases: } n=15(<8 \text { years of HT) } \\
\text { Cases: } n=21(\geq 8 \text { years of HT) } \\
\text { Controls: } n=31(<8 \text { years of HT) } \\
\text { Controls: } n=32(\geq 8 \text { years of } \\
\text { HT) }\end{array}$ & 9 \\
\hline Rudnicki, ${ }^{9}$ & $\begin{array}{l}\text { Case- } \\
\text { control }\end{array}$ & USA & $\begin{array}{l}\text { Cases: } n=40 \\
\text { Controls: } n=33\end{array}$ & $\begin{array}{l}\text { Cases: } \\
63,2 \pm 8,4 \\
\text { Controls: } \\
60,8 \pm 10.1\end{array}$ & $\begin{array}{l}\text { Cases: ND } \\
\text { Controls: } \\
\text { ND }\end{array}$ & $\begin{array}{l}\text { Cases: } 45,8 \\
( \pm 7,7) \\
\text { Controls: } 45,2 \\
( \pm 8,1)\end{array}$ & $\begin{array}{l}\text { Cases: } n=21 \text { (NA) } \\
\text { Controls: } n=11 \text { (NA) }\end{array}$ & 9 \\
\hline
\end{tabular}

Captions: NA: not available; SD: standard deviation; HT: hormone therapy; NOS: Newcastle-Ottawa Scale

\section{RESULTS}

The search strategies resulted in ninety-six articles, of which only four were in line with our objectives. The main reasons that led to article exclusions were a subject not related to our objective, animal experiments, and articles written in a language other than Spanish, English, or Portuguese.

\section{Study characteristics}

All four articles are observational studies conducted in different countries (USA, Italy, Ireland, and the Netherlands). Of these, one was a multicenter study conducted in the Netherlands, Ireland, and Italy. The number of patients analyzed in the four studies was 964 women with ALS and 2053 controls.

The two articles with the lowest number of cases and controls were the research conducted by Rudnicki ${ }^{9}$, which presented the lowest number of cases $(n=40)$ and controls $(n=33)$, and Popat et al. ${ }^{8}$, with 62 cases and 131 controls. Of the four included studies, only research conducted by De Jong et al. ${ }^{7}$ did not present the number of cases and controls that used hormone therapy and for how long the therapy lasted. The age range between patients and controls in the studies analyzed was 63 to 67 years old. Postmenopausal ALS patients were defined as cases and surveyed through a medical questionnaire, their use or not of hormone therapy. The controls were postmenopausal women at risk for ALS, and through a medical questionnaire, it was surveyed whether or not they used estrogen hormone therapy. In the studies considered, it is unclear which hormone therapy regimen was employed as well as the doses. These women had menarche within the same age group, at thirteen years of age, and menopause (naturally occurring) at between 49 and 52 years.

Quality assessment of the selected studies All selected studies achieved a NOS score of 8.5. The articles presented problems in the selection of controls and proof of exposure ${ }^{11}$.

\section{Result analysis synthesis}

In each selected study, we observed the age women entered menopause (cases and controls). We also observed how many of them underwent hormone therapy and its duration, and whether or not there was a reduction in the risk of ALS among those who underwent exogenous estrogen therapy when compared to those who did not.

When observing the percentages between cases and controls, we found, in studies conducted in the United States, a higher percentage of hormone therapy use by confirmed ALS patients ( $52 \%$ to $58 \%$ ) when compared to control patients (33\% to $48 \%$ ). The opposite occurred in studies conducted in European countries, where we observed greater adherence to therapy by control patients (17\%) to the detriment of confirmed ALS patients (14\%).

De Jong et al. ${ }^{7}$, in a study conducted in the Netherlands, did not provide the number of women who used hormone therapy and for how long they did it. In this study, they only identified the age of menarche and the occurrence of menopause, thus calculating the time of exposure to endogenous estrogen. In the same study, 
the age at which patients had the first symptoms of ALS was provided, which on average was around 64 years of age, and $57 \%$ of these women developed the bulbar form of the disease, considered the most severe and rapidly evolving. Only in the study by Popat et al. ${ }^{8}$, there is mention of the period of hormone therapy usage, both by cases and controls.

Another important finding was presented by the study by Rooney et al. ${ }^{6}$, conducted in the Netherlands. There was a reduction in the risk of developing ALS with the use of hormone therapy. There are two possible hypotheses for obtaining these results, one of them being the low prevalence regarding the use of hormone therapy in the other locations of the study compared to the Netherlands, where $10.25 \%$ of the number of cases underwent estrogen therapy, whereas, in the controls, $15.9 \%$ made use of hormone therapy. Another hypothesis would be the hormone therapy formulation used by the women participating in the study. In the same study, however, when we look at data obtained from women in the USA, the opposite was observed in comparison to those located in the Netherlands. In American women, there was an increased risk of ALS when they underwent hormone therapy.

\section{DISCUSSION}

The literature states that ALS presents itself as a disease with higher prevalence among men compared to women up until the moment these women enter menopause, when the number of cases is practically equal ${ }^{2}, 7,9$. During this period, not only a drastic decrease in estrogen levels occur, but also a slight increase in the blood plasma level of androgen in postmenopausal women, produced by the ovaries or the adrenals, which may explain the tendency to equate the ALS occurrence numbers between the two sexes ${ }^{2},{ }^{7}$. This leads us to believe in a possible neuroprotection by the female hormones action, especially endogenous estrogens ${ }^{2}$. Thus, our review aims to focus on the possible protective action of estrogen in the form of postmenopausal hormone therapy to reduce the risk of developing ALS76-9.

As we observe the selected studies and their differences in the use of hormone therapy between ALS cases and postmenopausal controls, there is a relatively small variation in the percentage of women who underwent or not hormone therapy. However, we found a significant difference when comparing the use of hormone therapy between studies conducted in
European countries and those conducted in the $\mathrm{USA}^{6}{ }^{6}$. In European countries, there is a greater adherence to hormone therapy by control patients than among ALS cases, whereas in US studies the opposite occurred. There was greater adherence to hormone therapy by confirmed ALS cases when compared to control patients. Even with this difference between participating countries in the use of exogenous hormones, there was no reduction in the risk of developing $\mathrm{ALS}^{6}{ }_{-}$.

Contrary to expectations, in some studies, ALS symptoms appeared earlier among women who used exogenous estrogen therapy. However, some studies compared the possible protective action of endogenous estrogen with the action of hormone therapy and found that women who had been on endogenous estrogen for a longer period (time between menarche and menopause) had a lower risk for ALS as well as a slightly longer survival time compared to those using exogenous hormone ${ }^{6}-9$.

According to Rooney et al. ${ }^{6}$, among the included countries, only the Netherlands presented a beneficial relationship with the use of hormone therapy, reducing the risk of amyotrophic lateral sclerosis. The reason for the difference between the three countries cited in this study is not very clear. Among the hypotheses raised, the low prevalence of hormone therapy use by other countries compared to the Netherlands is one of them. A second hypothesis would be the different formulations of hormone therapy that would be used in the Netherlands. The cases described in the Netherlands, however, are an exception among the observed studies. Studies showing a possible protective action of estrogens report endogenous estrogen exerting greater neuroprotective action than exogenous estrogen ${ }^{2},-99$, ${ }^{12}$.

There are some possible mechanisms of endogenous estrogen protection. One of which would be the probable preventive action of the disease onset, promoting a direct action of cell survival by preventing cell death (acting on the apoptosis cascade), increasing the release of neurotrophins, interacting with neurotransmitters, or providing antioxidant and anti-inflammatory benefits ${ }^{2},{ }_{-}^{6},{ }^{12}$.

Some in vitro studies corroborate the idea of endogenous estrogen neuroprotection, in which treatment or pretreatment with estrogen use in spinal and cortical motor neurons cell culture was observed ${ }^{26-9}{ }_{-}{ }^{12}$. Those studies showed that $17 \beta$-estradiol and $17 \alpha$-estradiol protected these neurons from glutamate toxicity and NO-induced cell death. 
These differences lead us to deduce that there is a possible protective action conferred by estrogen, since it was observed that the protection of these women would be linked to endogenous estrogen, and at the moment these women enter postmenopause, we observed increased risk of $\mathrm{ALS}^{2},{ }_{-}^{6}{ }_{-9}{ }^{12}$.

Regarding the effectiveness or not of using hormone therapy as a protective method, when we look at the history of exogenous estrogen use as therapy, we could not observe a significant percentage of women who could have benefited from a reduced risk of ALS by using estrogen therapy, both in cases and controls, which may be related to the fact that estrogen would only have a preventive effect and was unsuccessful as a recovery treatment for cell damage. Once damage to the neurons occurred, the hormonal action would be ineffective in reversing the process ${ }^{2},{ }_{-}^{69},{ }^{12}$.

Doubts about the effectiveness of estrogen therapy in ALS cases increased interest in the research and development of new therapies. There is a large number of potential drugs that may improve the survival or slow down the disease progression in ALS patients, including the non-steroidal selective estrogen receptor modulators (SERMs) such as tamoxifen and raloxifene associated with riluzole or edaravone ${ }^{13}{ }^{15}$.

Raloxifene has estrogenic properties, but it still holds promise for future use as therapy. The mechanism of how it acts towards ALS has not been fully understood; however, Tamoxifen, which has been used as adjunctive therapy for breast cancer, may slow the progression of muscle strength loss in ALS patients associated with the regular use of riluzole or edaravone ${ }^{15},{ }^{16}$.

Although this systematic review presents strong points like the large number of women evaluated, as well as the use of a consensual scale for critical evaluation of the evidence, we found an important bias in the non-inclusion of the population homogeneity regarding the information related to the use of hormone therapy (type and dosage) and how long it was used in some studies ${ }^{2}{ }_{-}^{6}{ }_{-9}{ }^{12}$.

\section{CONCLUSION}

We can conclude from observing the data provided by the selected studies that exogenous estrogen therapy did not have the desired beneficial effect when compared to the natural preventive protection of endogenous estrogen. In addition to not reducing the risk of ALS, the exogenous hormone has not been shown to increase the time of survival of these women.

\section{Disclosure}

On behalf of all authors, the corresponding author states that there is no conflict of interest.

\section{Author's Contribution}

Literature review: KV; manuscript writing: KV and MJBCG; data collection: KV, MJS and ASBO; data analysis: KV, LFPF, RSS, MJS and ASBO; manuscript reviewer: LFPF, MJS, ASBO and MJBCG.

\section{Glossary}

ALS: Amyotrophic Lateral Sclerosis; PRISMA: Preferred Reporting Items for Systematic Reviews and Meta-Analysis; NOS: Newcastle Ottawa Scale Critical Assessment Checklist; NO: nitric oxide; SERMs: selective estrogen receptor modulators; Ral: raloxifene

\section{REFERENCES}

1. Wijesekera LC, Leigh PN. Amyotrophic lateral sclerosis. Orphanet J Rare Dis. 2009; 4:3

2. Blasco H, Guennoc AM, Veyrat-Durebex C, Gordon PH, Andres CR, Camu W, et al. Amyotrophic lateral sclerosis: a hormonal condition? Amyotroph Lateral Scler. 2012;13(6):585-8.

3. Brown RH, Al-Chalabi A. Amyotrophic lateral sclerosis. N Engl J Med. 2017;377(2):162-72

4. Manjaly ZR, Scott KM, Abhinav K, Wijesekera L, Ganesalingam |, Goldstein $\mathrm{LH}$, et al. The sex ratio in amyotrophic lateral sclerosis: a population based study. Amyotroph Lateral Scler. 2010;11(5):439-42.
5. Moher D, Liberati A, Tetzlaff I, Altman DG; PRISMA Group. Preferred reporting items for systematic reviews and meta-analyses: the PRISMA statement. PLoS Med. 2009;21;6(7):e1000097.

6. Rooney JPK, Visser AE, D'Ovidio F, Vermeulen R, Beghi E, Chio A, et al. A case-control study of hormonal exposures as etiologic factors for ALS in women: Euro-MOTOR. Neurology. 2017;89(12):1283-90.

7. De Jong S, Huisman M, Sutedja N, van der Kooi A, de Visser M, Schelhaas J, et al. Endogenous female reproductive hormones and the risk of amyotrophic lateral sclerosis. J Neurol. 2013;260(2):507-12.

8. Popat RA, Van Den Eeden SK, Tanner CM, Bernstein AL, Bloch DA, 
Leimpeter A, et al. Effect of reproductive factors and postmenopausal hormone use on the risk of amyotrophic lateral sclerosis. Neuroepidemiology. 2006;27(3):117-21.

9. Rudnicki SA. Estrogen replacement therapy in women with amyotrophic lateral sclerosis. | Neurol Sci.1999;169(1-2):126-7.

10. Stang A. Critical evaluation of the Newcastle-Ottawa scale for the assessment of the quality of nonrandomized studies in meta-analyses. Eur | Epidemiol. 2010;25(9):603-5.

11. Ning L, Liu R, Lou X, Du H, Chen W, Zhang F, et al. Association between Helicobacter pylori infection and nonalcoholic fatty liver disease: a systemic review and meta-analysis. Eur J Gastroenterol Hepatol. 2019;31(7):735-42.

12. Garcia-Segura LM, Azcoitia I, DonCarlos LL. Neuroprotection by estradiol. Prog Neurobiol. 2001;63(1):29-60

13. ClinicalTrials.gov [internet]: State University of New York - Upstate Medica University. December 9, 2010. Identifier NCT01257581, Safety and Efficacy study of creatine and tamoxifen in volunteers with amyotrophic lateral sclerosis (ALS) (SDALS-001). [cited 2014 Dec 2014]. Available from: https:// clinicaltrials.gov/ct2/show/NCT01257581

14. ClinicalTrials.gov [internet]: Taipei Medical University Shuang Ho Hospital. June 18, 2014. Identifier NCT02166944, Tamoxifen treatment in patients with motor neuron disease. [cited 2019 Sep 19]. Available from: https:// clinicaltrials.gov/ct2/show/NCT02166944

15. Zhou Z, Ribas V, Rajbhandari P, Drew BG, Moore TM, Fluitt AH, et al. Estrogen receptor $\alpha$ protects pancreatic $\beta$-cells from apoptosis by preserving mitochondrial function and suppressing endoplasmic reticulum stress. | Biol Chem. 2018;293(13):4735-51.

16. ClinicalTrials.gov [internet]: University of Wisconsin, Madison. September 21, 2005. Identifier NCT00214110, Tamoxifen therapy in amyotrophic latera sclerosis [ALS]. [cited 2015 Oct 5]. Available from: https://clinicaltrials.gov/ ct2/show/NCT00214110 